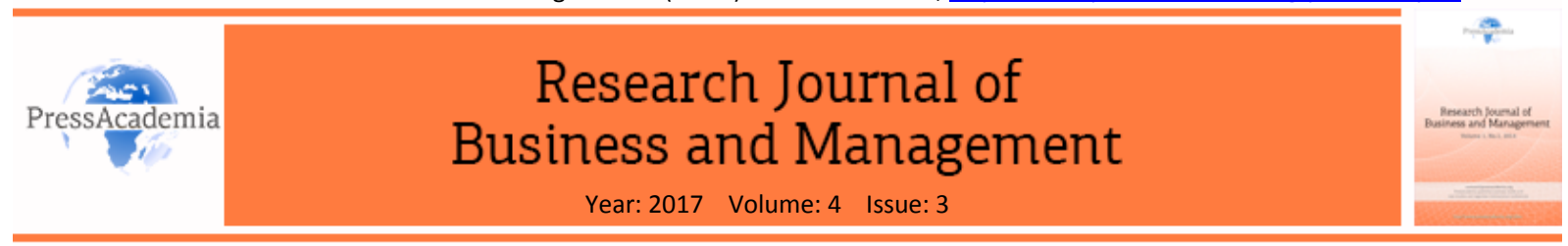

\title{
PRODUCT LIFECYCLE MANAGEMENT AS A WHOLE BUSINESS MANAGEMENT SYSTEM: AN EXPLORATORY RESEARCH
}

\author{
DOI: 10.17261/Pressacademia.2017.711 \\ RJBM-V.4-ISS.3-2017(10)-p.336-346
}

\author{
Efe Gurman ${ }^{1}$, Keti Ventura ${ }^{2}$, Haluk Soyuer ${ }^{3}$ \\ ${ }^{1}$ Aritmetrik PLM, Karşıyaka, İzmir, Turkey. egurman@aritmetrik.com \\ ${ }^{2}$ Ege University, Faculty of Economy and Administrative Sciences, Bornova, İzmir, Turkey. keti.ventura@ege.edu.tr \\ ${ }^{3}$ Ege University, Faculty of Economy and Administrative Sciences, Bornova, İzmir, Turkey. haluk.soyuer@ege.edu.tr
}

\section{To cite this document}

Gurman, E., K.Ventura and H. Soyuer, (2017). Product lifecycle management as a whole business management system: an exploratory research. Research Journal of Business and Management (RJBM), V.4, Iss.3, p.336-346.

Permemant link to this document: http://doi.org/10.17261/Pressacademia.2017.711

Copyright: Published by PressAcademia and limited licenced re-use rights only.

\begin{abstract}
Purpose - The aim of this paper is to define Product Lifecycle Management (PLM) Systems as a whole product focused management tool by featuring its importance for the enterprise integration management, product development and lean value systems.

Methodology - The paper is designed as an exploratory study consists of several interviews with senior managers of ELTAŞ Transformer Sanayi ve Ticaret A.Ş. about the process management capabilities of PLM systems within a case study.

Findings- The study reveals that non-technical processes like human resources can be managed using PLM methodology as well as the technical processes like product development. The results show the similarities of technical and non-technical processes, and show the possibility of managing even less technical processes to create a holistic business management tool.

Conclusion- The study shows the importance of the PLM systems for the product-focused management while the digital transformation of the production companies and their enterprise integration management and lean value systems.
\end{abstract}

Keywords: PLM, product lifecycle management, product based business management, new product realization, ERP JEL Codes: M11, M15

\section{INTRODUCTION}

PLM is a business strategy that is employed for the purposes of creating a business management setting with a focus on product data management. PLM first emerged due to the need for managing the complex product structures in automotive and aerospace industries and was composed of computer-aided design (CAD) and product data management (PDM) systems. Since then, it has developed capabilities that respond to the expectations of such disciplines as project management, process management, resource management and supply chain management; and it has reached its current form. PLM aims to ensure collaboration and communication between all stakeholders of a business and its suppliers throughout the entire life cycle of a product from design to post-sales service (Cantamessa, 2010). As a technology solution, it is based on a set of tools and technologies that create a data management platform for building collaboration between the stakeholders of a product which streamlines the flow of information at all stages of product life cycle. PLM is distinguished from other technological solutions not due to high technology tools but due to its capacity to create a sustainable business strategy.

Given the above, a brief overview of the history of PLM and a literature review are given in the first three sections of the paper. The fourth section includes a sample case study that explores PLM process management capabilities. Finally, both the findings regarding the enterprise chosen for the sample case study and some recommendations concerning the issue are presented in the last section. 


\subsection{Development of PLM}

With the invention of CAD systems in the early 1980s, a new era began for engineering design. It became possible to design geometric structures of products thanks to CAD systems. In the following years, engineering became dependent on computers as never before, with the development of computer-aided engineering and manufacturing systems (CAE/CAM). Before long, the need for a structured system to track the vast amount of data produced in considerably short times brought about the invention of product data management systems (PDM). This, as a result, made it possible to access technical and current product design process data in an easy, fast and reliable way. Early PDM systems could offer the required data to their users thanks to their capacity to work as central data stores. Besides, these systems entailed the capability to ensure data integrity which synchronized the data constantly and which aimed to monitor the way data were created and amended (Anwary, 2005). Over the years, PDM gained such new capabilities as engineering change management (Moon, 2011), document management, workflow management and project management and started to offer features ranging from concurrent engineering to cooperative product management within the business. At this stage, PDM covered data used solely in the area of engineering such as product development data, Bill of Materials, and finite element analyses (FEA); and therefore, less technical aspects like sales, marketing, supply chain management as well as external stakeholders like customers and supplier were excluded. Although web-based PDM systems started to emerge in the 1990s with the development of internet technologies, the use of these systems remained limited to engineering teams. Another development occurring in parallel to the development of PDM systems is observed in the area of enterprise resource planning (ERP). It has become possible to use material resource planning (MRP) algorithms thanks to the increasing calculative power of computers and to the rapidly growing access to these computers. On the other hand, these systems have become dependent on product data as never before. Besides, PDM systems have failed to respond to this need as they are developed on the basis of internal operation principle. The concept of PLM was formed in the 1990s so as to fill this gap. It has achieved to provide a platform that enables the use, organization and dissemination of the engineering knowledge of a product widely; and as a result, the concept of PLM has matured and gained its present status.

\subsection{The Effect of PLM on Enterprises}

Today, enterprises need more information as decision-making processes have gone more complex than ever. This necessity is included in the decision-making mechanism by collecting all the reports created in a business and by offering them to the business management authorities (Cantamessa, 2012). Therefore, the need for "objective information" for the transparency of a given business has become more important than ever. Data that constitute the basis of information represent the business-independent and unprocessed reality. In this regard, information can be considered to be the collection of data in a way that they can be used in the subject decision-making mechanisms. According to a study by Gartner and IDC (2012), $80 \%$ of the data available worldwide are not structured. It is not possible that these unstructured data could be used or could create value. PLM systems guide business managers in their decision-making processes since these systems cover all business stakeholders, are immune to manipulation and form a structured information resource. In order for this task to be fulfilled successfully, information should be fostered not only by engineering data but also by data produced by all the departments of a business.

\section{LITERATURE REVIEW}

\subsection{Enterprise Integration Engineering}

Enterprise integration is a domain of research that has been developed as an extension of computer-integrated manufacturing (CIM) since the 1990s. It mainly covers two research disciplines: Enterprise Modelling and Information Technology. Enterprise modeling refers to a group of concepts that are related to the definition of an architecture for an enterprise, to system-wide decision-making consistency and to a process beyond the borders of functions of workflow model as well as to the dynamic allocation of resources and data consistency (Peñaranda, 2010). As to the information technology, it aims to ensure the integration of the entire enterprise through the integration of such enterprise systems like ERP and PLM. According to enterprise integration, all these systems and practices should ensure the regulation of processes.

Enterprise integration engineering is a sum of modelling principles, methods and tools that ensure the integration of a variety of enterprise life cycle entities (e.g. project, product, processes, workflow, and documents). It relies on the creation of a business model by various enterprise elements (Peñaranda, 2010). Enterprise integration engineering enables the diffusion of enterprise strategies, which are based on corporate mission and vision, across key performance indicators, processes and products. A variety of tools are required to improve the synergy within an enterprise, to link all the functions to each other for the purposes of fulfilling the corporate mission and vision, to eliminate gray areas and to improve communication by means of this integration. Furthermore, enterprise integration engineering will ensure the coordination of business processes and build a decision-making culture based on cooperation. In the end, it will also enable data integration and hence enterprise integration. 


\subsection{Information Backbone}

All the individuals and systems in an enterprise should be interconnected so that enterprise integration can be achieved. Enterprises that generate individual solutions for distributed information systems and business metrics as well as for individual problems should eliminate complex data clusters that they produce. It is possible to overcome this problem through the use of a single database which is possible only if a single information backbone is created. In this regard, PLM systems run in coordination with ERP systems and enable an enterprise to realize an integration that is in line with its mission and vision and is under control at the same time.

\subsection{An Evaluation of ERP and PLM}

In the early 21st century, following the stage of transition to the next series after design freeze, ERP performed a range of tasks in production processes namely information storage, production work orders and material planning. Bill of materials (BOM) test procedures that constitute the core of this information are managed via tables and ERP systems for logistics. Through time, the task to update bill of materials used on ERP was transferred to PLM systems and hence, it became possible to eliminate any possible material resource planning (MRP) errors. In this way, problems of bill of materials that frequently occurred in many enterprises after engineering changes would be eliminated. The integration between ERP and PLM systems allowed sharing of engineering and manufacturing data within an enterprise in the form of an automated process (Cimalore, 2012). This enabled engineering, manufacturing, planning and purchasing departments to work in a connected way and promoted enterprise integration a step forward. Rapid development of wireless communication protocols allowed ERP systems to gain the support of manufacturing execution system (MES) applications. The capability to collect real-time manufacturing data was highly successful in the provision of the required data to MRP algorithms that work embedded in ERP systems. Over the years, development of these protocols resulted in the development of digital factory and Industry 4.0 approaches. Today, enterprises have control over their products and manufacturing areas more than ever thanks to the wide use and affordability of these technologies (Laroche, 2012). However, it emerges as a new challenge for enterprises to access to the vast amount of data produced via these communication means, to store the subject data and to use it as part of their decision mechanisms. Finally, storage of all these data and opening them to the access of humans and machines altogether have become tasks that are carried out by PLM systems.

\subsection{Business Processes and Corporate Memory}

Such key concepts as enterprise modeling, technology integration and the definition of an enterprise strategy bear crucial importance for building an enterprise integration model (Peñaranda, 2010). Enterprise modeling issue, also covered by the present study, necessitates the visualization of all enterprise processes in a way that depicts the whole picture. An enterprise model can be formed via induction by building a neural network that links all business processes to each other at necessary points (Corbett, 2000). An enterprise model is completed when each sub-process of each department is revised one-by-one and then the revised processes are connected to the enterprise backbone. This enables the creation of a lean enterprise model which is free from gray areas, waste, non-value-added tasks as well as from complex and repetitive processes.

Knowledge capital of enterprises has been gaining increasingly higher importance, and within this context, two new risks emerge for enterprises (Abel, 2008):

1. Lack of Environmental Knowledge (technologies, competitors, markets, etc.): Management of knowledge on the basis of flow system instead of a stock system so that a proper environment that lends itself to novelty can be prepared.

2. Loss of Knowledge and Competence: Losses of this type occur through time (retirement, termination of the employment of the key personnel, information change and so on). If knowledge and skills are utilized in only one part of the enterprise premises while it is deficient in other parts of the premises, such losses might occur.

Both cases might entail destructive results for enterprises. Lean enterprise model achieved by enterprises, which are living organisms, transforms rapidly in the face of changing conditions. Nevertheless, it is obvious that any error spotted in process analyses should be corrected in real time. Restriction of these corrections to single practices means that any acquired knowledge is not written on organizational memory and this causes the above-mentioned two risks to arise. Enterprises should, with the help of technological support, be able to build their process in a way that any process improvement can be used in the following stages as well. In this regard, technological support is used to refer to wellstructured databases. When the process is given a start, tasks should be assigned to respective roles in a way that they contain this new knowledge and any possible errors should be prevented. Customizable process management capabilities in PLM systems will be addressed in the following parts. 


\section{PRODUCT MANAGEMENT-ORIENTED BUSINESS MANAGEMENT}

In a globalizing world of fierce competition, renewal and development of products and equipping these products with innovative features have become more important than ever for the success of enterprises. On the one hand, enterprises strive to adapt their strategies to the competition conditions. On the other hand, they try to build waste eliminationoriented lean value systems and to reduce their costs. Diffusion of this idea beginning from the business strategy to the entire enterprise body is expressed as a lean value system. Lean value systems are analyzed in two parts namely diffusion of strategy defined in Figure 1 and leaning of all processes in a holistic approach (Hines, 2005).

Figure 1: Strategical Thinking implemented on Lean Organizations

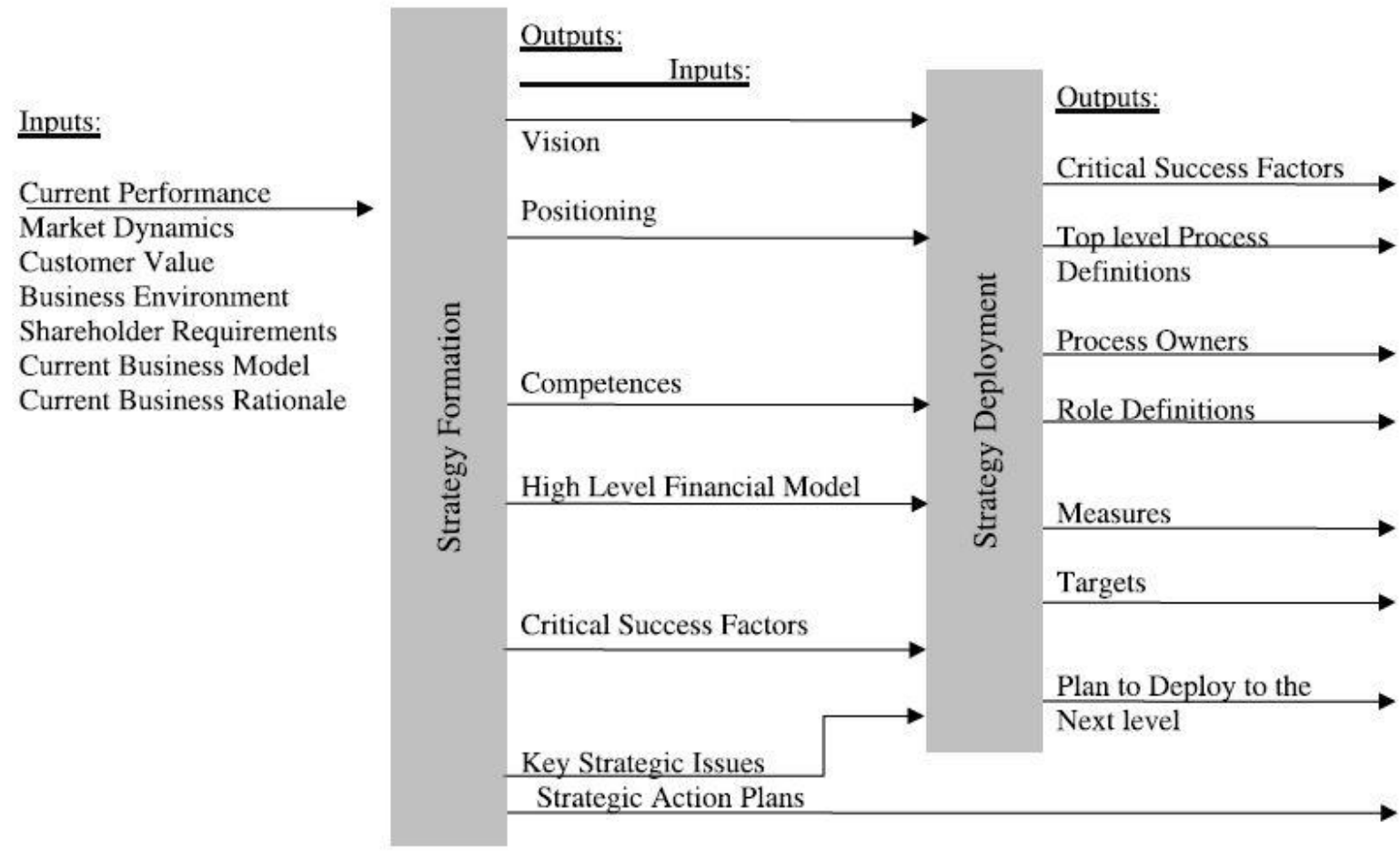

Source: S A Partners, 2004

Enterprises are required to integrate their decision-making mechanisms into this system in order to create a lean value system. This integration necessitates that the data to be used in decision mechanisms are fast, accessible and reliable. In order to build a lean management system, the information to be used in decision mechanisms must also be democratized. Decisions reached on the basis of reports issued by department managers might raise problematic results. Democratized information can be defined as the piece of information accumulated and structured without being filtered through individuals' subjective filters. It refers to the data that come from organizational memory, are verified via control parameters and are structured. Such a data source enables access to a decision mechanism that is free from personal interests (Bose, 2006).

PLM systems involve, as part of their nature, lean data from many data sources. Meaningful information packages and reports that can be used by the business management should be created for the accumulation of these data without a mediator. Processes, products, projects, documents, parameters, reports and nonconformities are connected to one single information backbone in PLM systems (Figure 2). Connections that are built within this backbone will ensure the construction of one single information pool. 
Figure 2: Information Backbone of All Business Processes

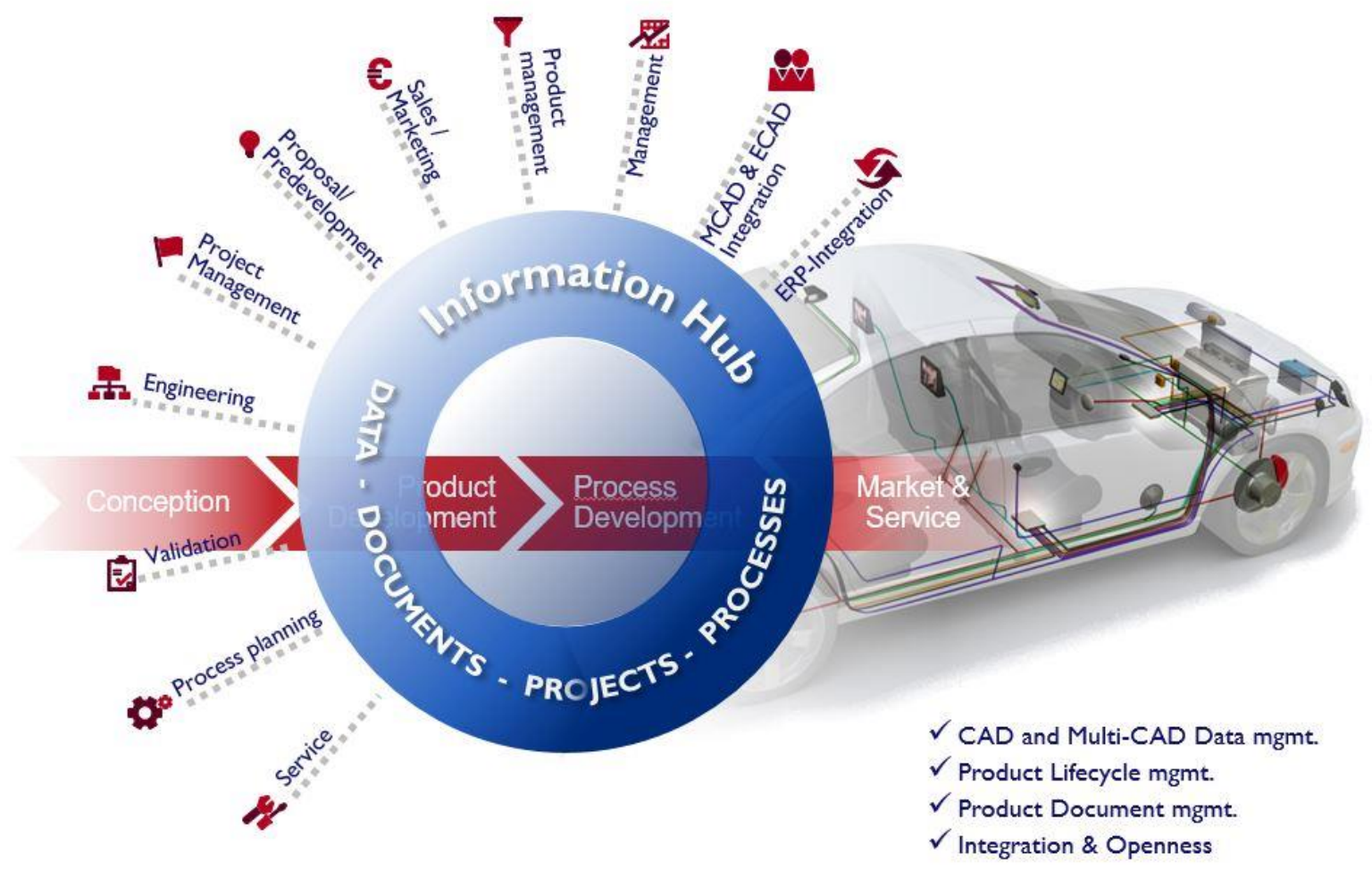

Source: CONTACT Software, 2015

In the complex organizations of our age, employees are expected to deal not only with their fundamental duties but also with bureaucratic procedures. As a consequence, wastefulness rises and more importantly the time during which creative thinking outputs could be delivered is, instead, spent on non-value-added tasks. Leaning of processes is possible only after processes are clarified. Mail boxes of employees evolve into a data center and a to-do-list due to gray areas inherent in processes and errors in the description of responsibilities. If these processes are structurally diverted to those in charge in the form of a task-based set-up, the result will be leaning. Process editing tools of PLM systems allow processes to be defined in a form that they are integrated with nets and products, projects, and quality systems. In the light of the research conducted by CIMDATA (2011), recognized as a global authority in the field of PLM and business processes, the relationship between PLM use and waste items in product development processes is presented in Figure 3. 
Figure 3: The Effect of PLM Practices on Product Development Waste

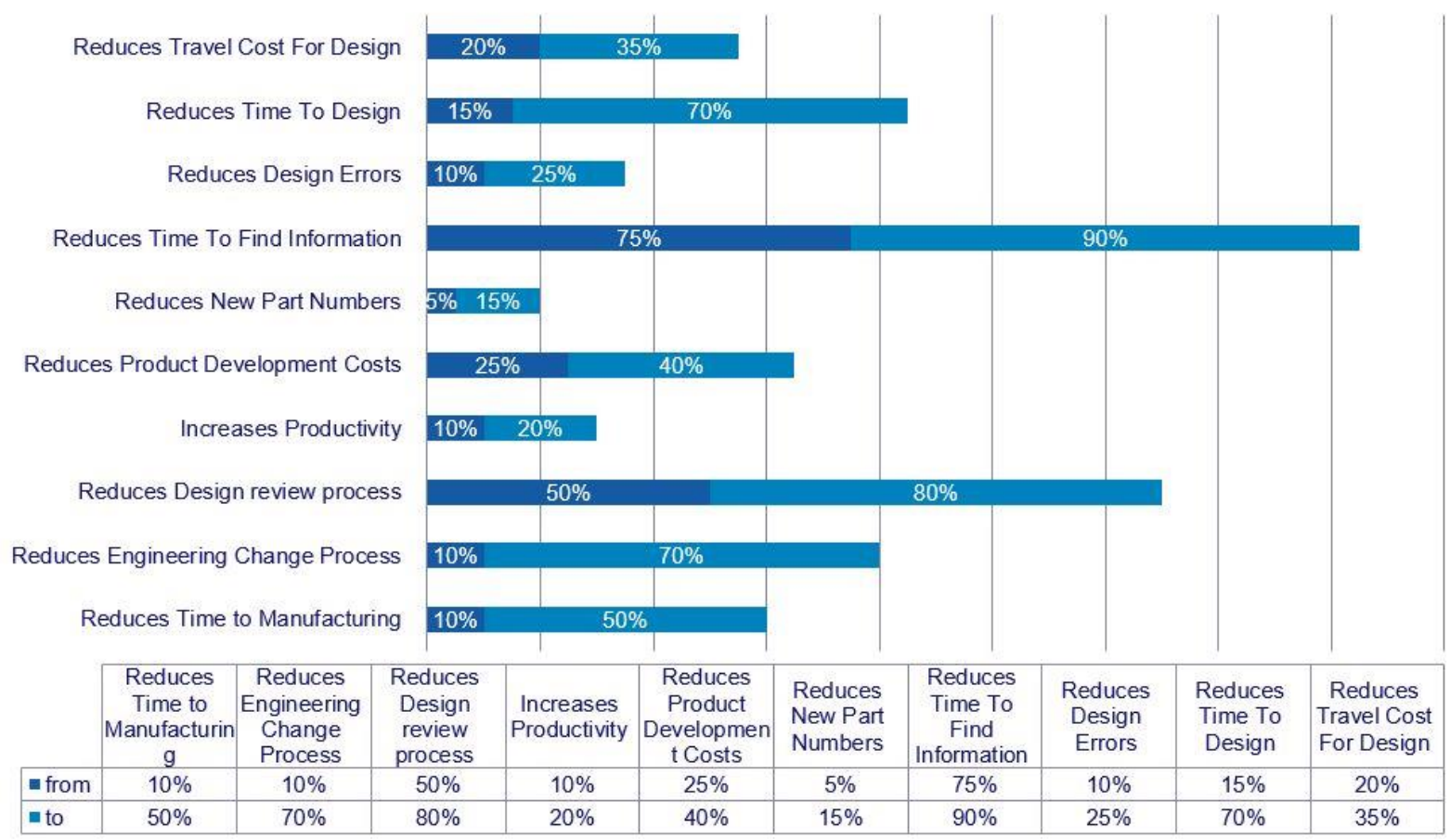

Source: CIMDATA, 2011

\section{A CASE STUDY ON PRODUCT MANAGEMENT-ORIENTED BUSINESS MANAGEMENT}

In this part of the study, in cooperation with ELTAŞ Transformer Sanayi ve Ticaret A.Ş. [Transformers Industry and Trade inc.], the usability of PLM practices not only in product development processes but also in all business processes as well as the possibility of extending PLM practices from quality management system to maintenance and repair management system and from production planning to training process were evaluated.

Eltaş joined business life in 1981 in the area of production and sales of oil test and oil treatment devices. The company began to manufacture oil-immersed transformers in 1995 and was accredited with ISO TS: 9001 certification in 1996. In 2001, the company realized its first export deal and in 2005, it started to manufacture dry type transformers. Today, the company largely exports its products and operates in Çiğli Atatürk Organized Industrial Zone and Aliağa Organized Industrial Zone

\subsection{Purpose, Scope and Limitations of the Study}

The purpose of the study is to show that contrary to the current tradition of using PLM systems for product development, it is possible that PLM systems are used to manage all technical or non-technical processes in a way that they are also integrated with products, projects and documents. As to the scope, sample processes, information about which was obtained from the enterprise, were selected. Process charts were included in these processes and the workflow on the process charts was integrated in the PLM system. The adopted PLM system did not contain any information about the company, and therefore, this resulted in a limitation as processes could not be integrated in CAD systems, documents and projects.

\subsection{Methodology of the Study}

In accordance with the purpose of the study, a qualitative research method was employed. In the study, interview method, the most common data collection method in qualitative research, was utilized. In-depth interviews were conducted with senior managers of ELTAŞ Transformer Sanayi ve Ticaret A.Ş. using a pre-defined standard list of questions. 
In the present study, qualitative case study design was adopted. Case study, a qualitative research type that helps researchers exploring the answers to the questions "how" and "why" study a case or event, is a comprehensive and systematic model. In the study, purposive sampling method was also utilized. Purposive sampling method is used for the discovery and explanation of cases and events (Yıldırım and Şimşek, 2006). Typical case sampling, a purposive sampling method, was selected for the study purposes. The reasons why ELTAŞ Transformer Sanayi ve Ticaret A.Ş. was chosen as the agent in the case study was that it has its own research and development (R\&D) and product development capacity and that it is a technical manufacturing company that can realize both project-based and mass production.

\subsection{Findings}

After the study, it was ensured that all processes, regardless of whether they were related to product development or whether they were non-technical, were integrated in the PLM system. In this way, it has been proved that all company processes and single tasks that make up these processes can be associated with those who are committed to the organizational roles of a given enterprise. This has also revealed that all reports and key performance indicators in the enterprise can be created via a PLM system.

\subsection{PLM in the Product Development Process}

ELTAŞ Transformer is engaged largely in project-based work. Therefore, all projects go through a set of development stages. At these stages, several teams in the company are required to undertake some duties. The subject teams are given below:

$\begin{array}{ll}\text { - } & \text { Sales } \\ \text { - } & \text { Electricity Project Preparation } \\ \text { - } & \text { Mechanical Project Preparation } \\ \text { - } & \text { Muality } \\ \text { - } & \text { Proderial Planning } \\ & \end{array}$

The first thing to do was to gather project information, and this task was assigned to the sales team; and the technical documents in the attachment of the proposal were linked to the task. In the PLM system shown in Figure 4, the same task was defined. According to this, the person in charge, deadline, attached documents and related processes were all linked to the task. According to this standard procedure, the task is assigned to the person who has held organizational roles and is experienced in this regard. The input of this stage is the technical documents of the proposal and the output will be project information. 
Figure 4: Task Outline in the Process of Electricity Project Preparation

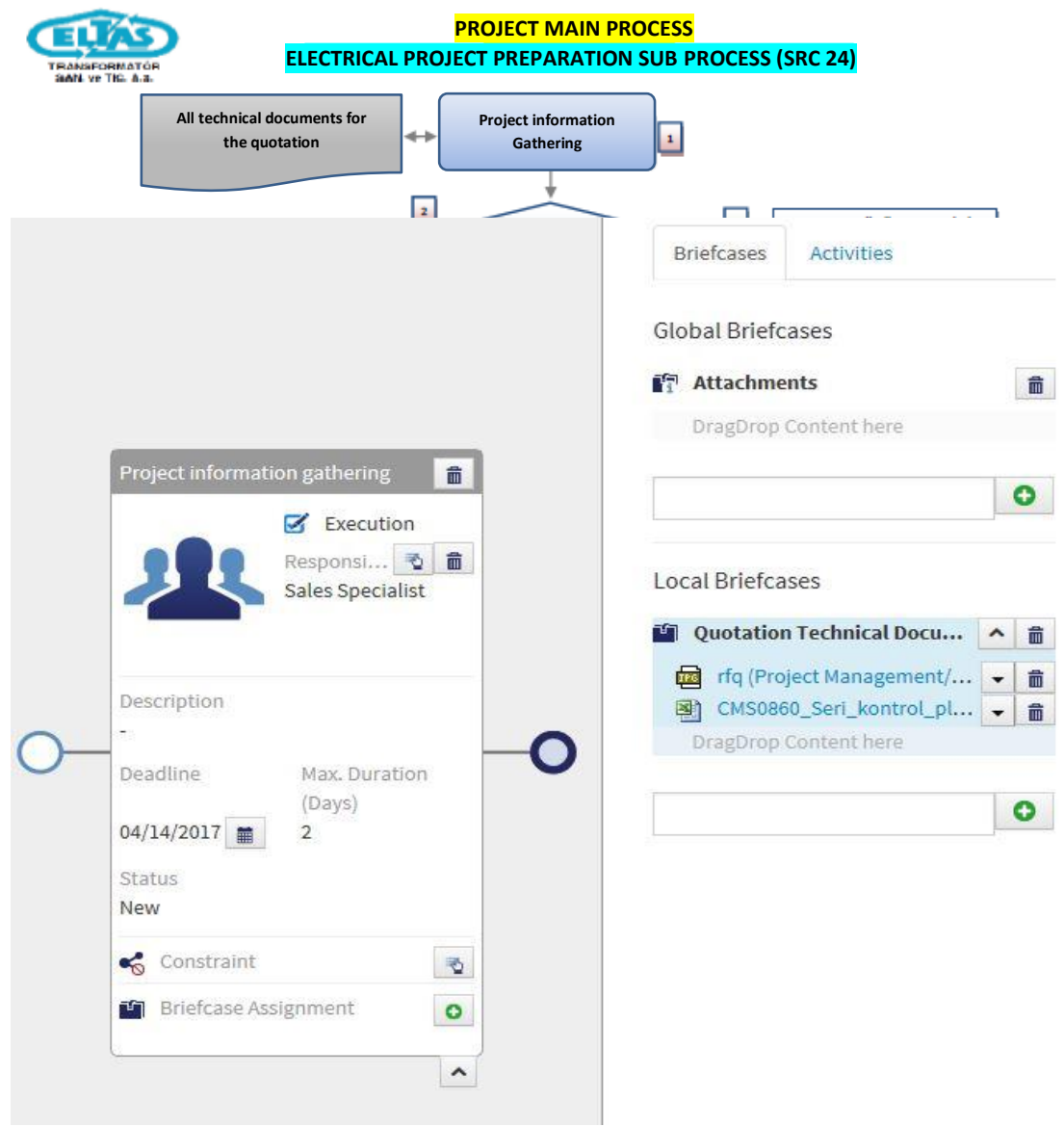

Source: ELTAŞ Transformer A.Ş.

The task responsible follows their tasks via the task manager. All information, documents and communication in relation to the task can be completed using the activities tab without losing time (Figure 5). 
Figure 5: Task Manager

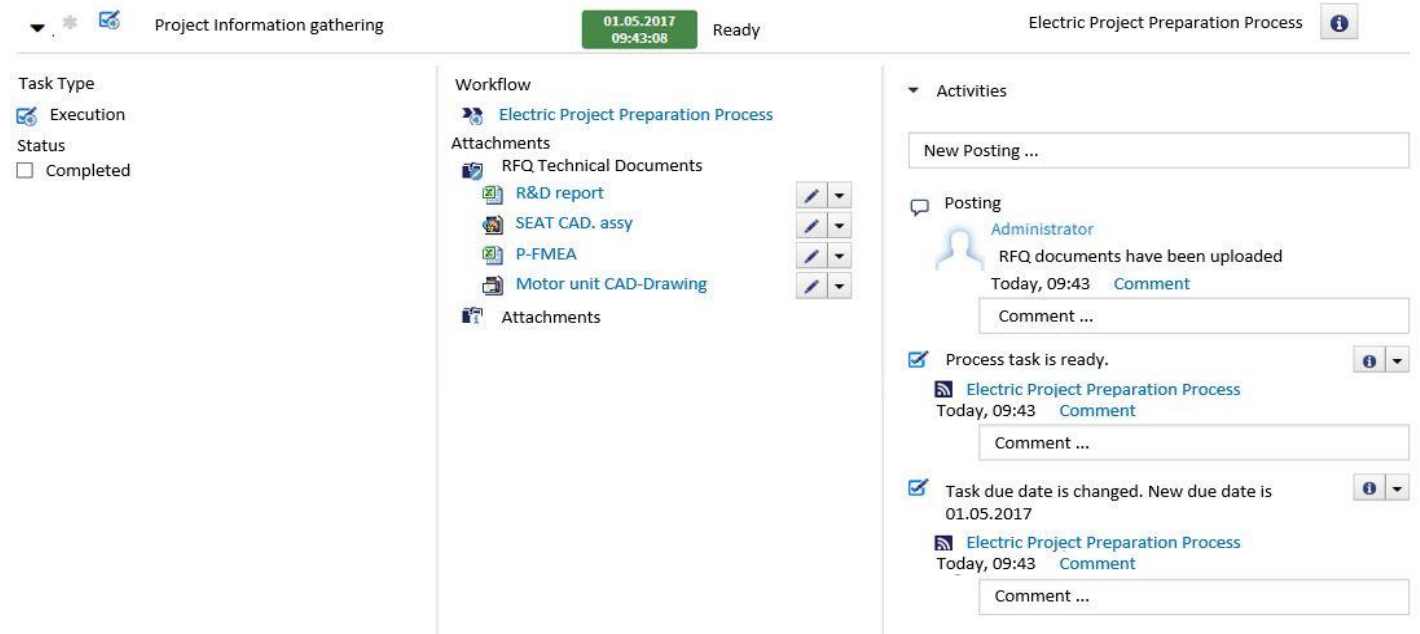

Source: CONTACT Software GMBH

The difference in PLM systems is that the task is associated both with the CAD documents and the process. For this reason, both the completion of the task and the execution of the process were included in the life cycle of the product and it became possible to trace them in the future.

With the completion of this process together with other tasks, product development stage will have been finished and the time required to gain access to information will be minimized in order to make it easier for individuals to fulfill their fundamental duties. The entire process is shown in Figure 6.

\section{Figure 6: Electricity Project Preparation Process}

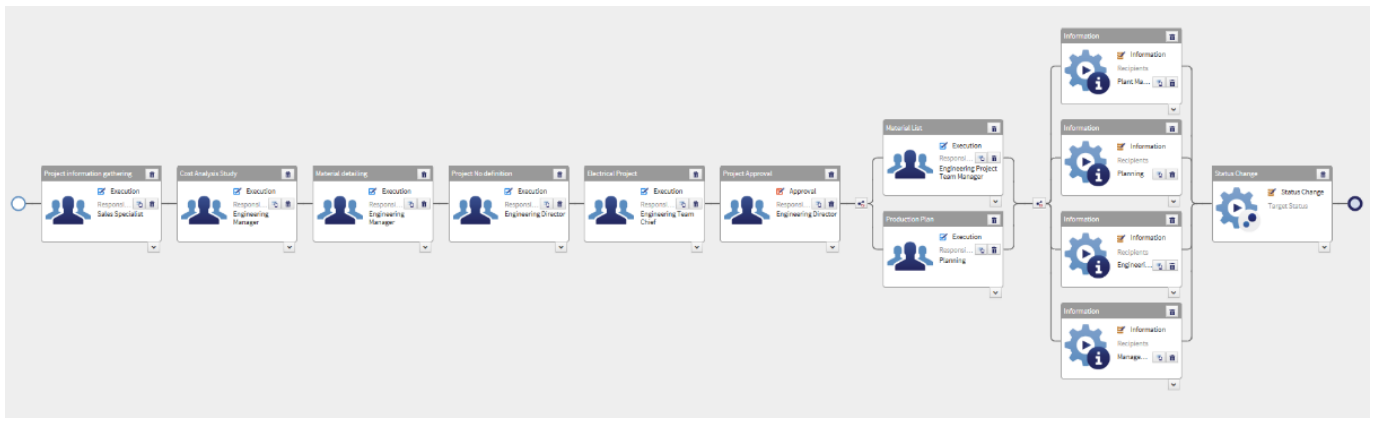

Source: CONTACT Software GMBH

\subsection{PLM for the Management of Non-Operational Processes}

Human resources practices can be considered as examples of non-operational processes. Figure 7 shows the product development process together with human resources process. Although the two processes have highly different input and outputs, the way they are realized is quite similar. In the product development process, product-related objects were linked to the process steps; while in human resources process, it was training objects that were linked to the process. Majority of the objects that are associated with PLM processes will change with the execution of these processes and documents will be disseminated within the enterprise after the process is completed. Automatic information tasks were included in the processes in order to update the required persons or roles about the process development. 


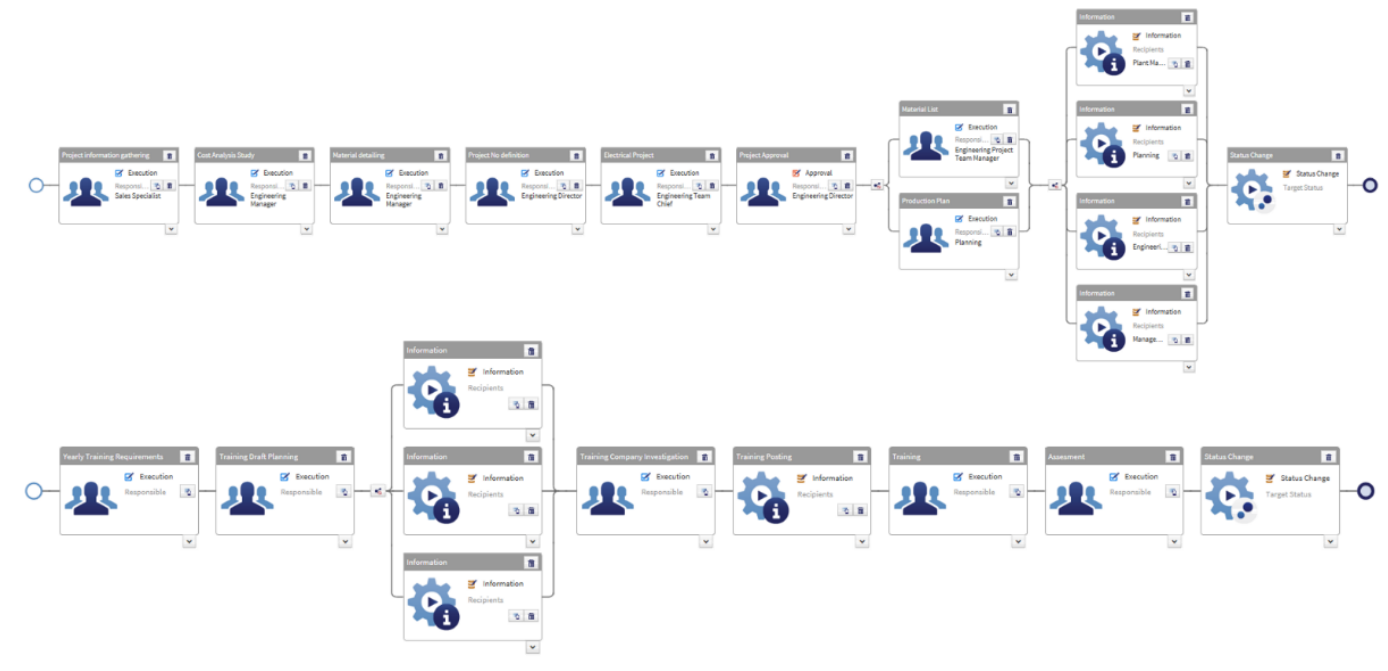

Source: CONTACT Software GMBH

\subsection{Enterprise Cockpit from the Perspective of Senior Management}

As also stated in the previous sections, information that the management mechanism needs should be provided by democratized sources. It is necessary that these sources should be verified by control variables and that their objectivity is ensured. Databases in PLM systems are immune to manipulation and are independent data sources. Each part provides only the piece of data that is related only with the subject part. The whole that is formed by the combination of these information clusters are not subject to the control of any individual or role and have a democratic structure. Using the subject data as a source of reporting data became possible when the business management accessed to the required piece of objective data.

\section{CONCLUSION}

Enterprise processes should be related to products and derive information from product requirements. If these requirements are supported via customer requests, the value chain will be sustained including even the most detailed process step. Similarly, enterprise integration engineering works towards the same end, that is, to ensure the integrity of the chain. Lean value systems focus on the reduction of process waste by means of constant improvement strategies. PLM systems have, for years, been fulfilling their initial duty of managing product development processes and ensuring quick entry into the market. In addition, PLM is a body of systems that offer enterprises integrated enterprise entities that are required for enterprise integration engineering in addition to the opportunity for process improvement required for lean value systems and the chance to record these improvements in the organizational memory. Besides, it enables enterprises to develop decision-making mechanisms based on objective information and makes it possible to run proactive measure mechanisms. The importance of a product management-based strategy will grow even higher at the digital transformation stage, a vital turning point awaiting the industry. Product management based information backbones of PLM systems are among the systems frequently adopted by enterprises undertaking Industry 4.0 transformation (Laroche, F, 2012). Under these conditions, it is expected that a frequent practice of Turkish enterprises within the next decade will be realizing their integration in favour of PLM practices. 


\section{REFERENCES}

Abel, M. (2008) "Competencies management and learning organizational memory", Journal of Knowledge Management, Vol.12 Issue: 6 , pp.15-30

Anwary, M. (2005), Thesis, B.Sc.: “An Open Lifecycle Management System”, Ryerson University

Bose, R. (2006) "Understanding management data systems for enterprise performance management", Industrial Management \& Data Systems, Vol. 106 Issue: 1, pp.43-59

Cantamessa, M., Montagna, F., Neirotti, P. (2012),"Understanding the organizational impact of PLM systems: evidence from an aerospace company", International Journal of Operations \& Production Management, Vol. 32 Iss 2 pp. 191 - 215

Cimalore, C. (2012) “Create collaboration between ERP and PLM", Plant Engineering July/August 2012 pp. 29-32

CIMDATA LLC. (2011), "Product Lifecycle Management and the Data Deluge, transforming data to enhance performance", http://www.cimdata.com/en/component/docman/cat_view/43-complimentary-reports/50-whitepapers

CONTACT Software GmbH, (2015) “CIM Database PLM Presentation”

CONTACT Software GmbH, CIM Database PLM Software V 11.0 Workflow Management and Task Manager Modules Screenshot

Corbett, J. M. (2000) "On being an elephant in the age of oblivion: Computer-based information systems and organisational memory", Information Technology \& People, Vol. 13 Issue: 4, pp.282-297

ELTAŞ Transformer A.Ş., "New Product Development Procedure”

Emerald Group Publishing Limited (2007) Information backbone: strong PLM investment. Strategic Direction 23(8): 32-34

Emerald Group Publishing Limited (2008),"Closing the PLM loop: The promise of capturing whole life product data", Strategic Direction, Vol. 24 Iss 4 pp. 35 - 37

Contact Software Corporate Report, (2015), Bremen Germany

Gecevska, V., Stefanic, N., Veza, I., Cus, F. (2012) "Sustainable business solutions through lean product lifecycle management", Bulletin of Engineering Tome V, Fascicule 1 pp. 135-142

Hines, P., Francis, M., Found, P. "Towards lean product lifecycle management: A framework for New product development", Journal of Manufacturing Technology Management, Vol. 17 Iss 7 pp. 866-887

Laroche, F., Bernard, A., Bordeu, F., Chinesta, F. (2012) "Towards the factory of the future: An integrated approach of material-processesinformation-human being"

Moon, Y. B. (2011), “Modeling and managing engineering changes in a complex product development process", 2011 Winter Simulation Conference

Otto, B. (2012),"Managing the business benefits of product data management: the case of Festo", Journal of Enterprise Information Management, Vol. 25 Iss 3 pp. $272-297$

Peñaranda, N., Mejía, R., Romero, D., Molina, A. (2010) "Implementation of product lifecycle management tools using enterprise integration engineering and action-research", International Journal of Computer Integrated Manufacturing, 23:10, 853-875

S A Partners (2004), Strategy Formation \& Deployment, Unpublished Presentation.

Yıldırım, Ali ve Hasan Şimşek (2008), Sosyal Bilimlerde Nitel Araştırma Yöntemleri, 7. Baskı, Seçkin Yayıncılık, Ankara 